\title{
Walking the walk: The moderating role of proactive parenting on adolescents' value-congruent behaviors
}

Laura M. Padilla-Walker

Brigham Young University, laura_walker@byu.edu

Ashley M. Fraser

James M. Harper

Follow this and additional works at: https://scholarsarchive.byu.edu/facpub

Part of the Social and Behavioral Sciences Commons

\section{Original Publication Citation}

Padilla-Walker, L. M., *Fraser, A. M., \& Harper, J. M. (2012). Walking the walk: The moderating role of proactive parenting on adolescents' value-congruent behaviors. Journal of Adolescence, $35,1141-1152$.

\section{BYU ScholarsArchive Citation}

Padilla-Walker, Laura M.; Fraser, Ashley M.; and Harper, James M., "Walking the walk: The moderating role of proactive parenting on adolescents' value-congruent behaviors" (2012). Faculty Publications. 4935. https://scholarsarchive.byu.edu/facpub/4935 


\title{
Walking the walk: The moderating role of proactive parenting on adolescents' value-congruent behaviors
}

\author{
Laura M. Padilla-Walker*, Ashley M. Fraser, James M. Harper \\ School of Family Life, Brigham Young University, Provo, UT 84602, USA
}

Keywords:

Value-congruent behaviors

Values

Proactive parenting

\begin{abstract}
A B S T R A C T
The current study longitudinally examined adolescents' internalization of values in four domains (drug use, prosocial, school, friends), and how these values were differentially related to behaviors (delinquency, prosocial behavior, school engagement, and deviant peer association) as a function of proactive parenting. Participants included 335 adolescents ( $M$ age of child at Time $2=12.28, \mathrm{SD}=.99,51 \%$ female) and their parents. Analyses examined associations between adolescents' values at Time 3 and corresponding behaviors at Time 4, and the moderating role of proactive parenting (assessed at Time 2 using cluster analysis). Results suggested that adolescents with the most consistent value-congruent behavior had parents who used deference or reasoned deference as an approach to proactive parenting, highlighting the importance of autonomy supportive parenting in the encouragement of self-generated values and corresponding behaviors. Discussion focused on value-congruent behaviors and associations between values and behaviors across domains.
\end{abstract}

(c) 2012 The Foundation for Professionals in Services for Adolescents. Published by Elsevier Ltd. All rights reserved.

Values are broad, stable goals or motivational constructs that communicate what is important to an individual (Schwartz, 1997) and are often assumed to be reflected in behavior, although there are mixed findings regarding whether or not this is the case (e.g., Bardi \& Schwartz, 2002). Most research examining the link between values and corresponding behavior examines individual values and behaviors in isolation, presuming that values operate within their specific domain. However, other studies have found that while there is significant value-behavior congruence, there is also considerable overlap between values in one domain and behaviors in a different domain (Bardi \& Schwartz, 2002; Mueller, 2006; Simons, Simons, \& Conger, 2004). Although these relations have been relatively well established in adult samples, these findings pay little heed to the socialization of values, and how the process of internalization may be influenced by parenting during the developmental years. The correspondence between values and behaviors (both within and across domains) is particularly important to examine during adolescence when children are increasingly able to reason at higher levels (Carlo, Eisenberg, \& Knight, 1992), are establishing values as part of their identity (Erikson, 1968; Knafo \& Schwartz, 2004), and are having these new values tested by sources outside the home, such as peers and media (Padilla-Walker \& Thompson, 2005). If one posits that values are linked to adolescents' behaviors and well-being (Hardy \& Carlo, 2005; Kasser, Ryan, Zax, \& Sameroff, 1995), it is important to understand the process through which values are acquired, and how socialization might foster correspondence between values and behaviors, both within and across domains. Thus, the current study used a longitudinal approach to examine adolescents' internalization of values in four domains (drug use, prosocial, school, friends), and how these values

\footnotetext{
* Corresponding author. Tel.: +1 801422 9053; fax: +1 8014220230.

E-mail address: laura_walker@byu.edu (L.M. Padilla-Walker).
} 
were differentially related to behaviors (delinquency, prosocial behavior, school engagement, and deviant peer association) as a function of parental socialization.

\section{Internalization of values}

Self-Determination Theory (SDT) suggests that internalization of values is the process through which children and adolescents acknowledge values and then integrate them into their own identities (Deci \& Ryan, 1991; Grusec, 2002; Grusec \& Goodnow, 1994), resulting in behaviors that are self-regulated (Grolnick, Deci, \& Ryan, 1997). The developmental study of values lends itself to examining the reasons or motivations for adolescents to endorse a particular value, and the degree to which it is truly self-generated. Deci and Ryan (1991) added to this notion, explaining that values and behaviors should be distinguished in the degree to which they are extrinsically (where behavior is motivated by some external source, such as parents) or intrinsically (where behavior is done freely and spontaneously with little regard to consequence) motivated. More specifically, SDT distinguishes four types of regulation. First, behavior can be a result of external regulation, meaning values and behavior are controlled through punishment or reward. Introjected regulation involves values being taken in but not fully accepted, meaning behavior is still motivated through external sources such as norms or expectations, and by guilt and blame avoidance. Identified regulation is where individuals accept values because they identify with the importance of them and their corresponding behaviors. Finally, integrated regulation means values are fully incorporated with the individual's sense of self, and are in unity with other values, goals, and motivations. Thus, at the lower two levels (external and introjected), valuecongruent behavior, or behavior that is consistent with one's values, is a result of compliance or control; whereas at the two higher levels (identified and integrated), value-congruent behavior is self-generated and autonomous.

This distinction between externally and internally regulated values is important because adolescents whose values are more internally regulated should display more congruence between values and behaviors because when behaviors are selfgenerated they fill one's need to feel competent and are more self-defining (Deci \& Ryan, 2000), whereas behaviors that are externally regulated have little incentive and are not likely to be generalized across domain and context. As previously mentioned, there are few studies that examine the congruence between values and behaviors in multiple domains. Thus, the current study will focus on four domains that are relevant to the developmental time period of adolescence, namely values surrounding the avoidance of drug use, prosocial behavior or benevolence, academic achievement, and choosing good friends.

\section{Congruence between values and behaviors}

Adolescence is often associated with increased experimentation with substance use and delinquency (Siegel \& Scovill, 2000), which when occasional does not have marked deleterious outcomes, but when frequent has been associated with multiple risky outcomes including lower psychosocial adjustment and health risk. However, internalization of positive values (e.g., benevolent values such as kindness and honesty) can serve as a protective factor against delinquency and drug use, evidenced by studies suggesting that having internalized moral or prosocial values has been negatively associated with delinquent behavior (Tarry \& Emler, 2007), risky sex (Ludwig \& Pittman, 1999), and hard drug use (Allen, Leadbeater, \& Aber, 1990) during adolescence. In addition, a lack of conventional or social values has been associated with antisocial behavior, as well as residence in juvenile delinquency and rehabilitation centers (Romero, Sobral, Luengo, \& Marzoa, 2001). We are not aware of studies that have examined values specific to the domain of drug use, so the current study will examine values regarding the avoidance of drug use as a predictor of delinquency.

In addition, by adolescence prosocial behavior is relatively stable and has been associated with numerous positive outcomes, including increases in self-efficacy and self-esteem (Bandura, Caprara, Barbaranelli, Pastorelli \& Regalia, 2001; Laible, Carlo, \& Roesch, 2004), as well as decreases in anxiety, anger, and trouble at school (Diener \& Kim, 2004; Eisenberg et al., 1996). A sizable body of research has examined the importance of prosocial or benevolent values as they relate to a variety of positive outcomes during adolescence. Namely, prosocial values have been linked to greater levels of prosocial behavior (Padilla-Walker, 2007; Padilla-Walker \& Carlo, 2007), as well as to lower levels of delinquency, risky sexual behavior, and drug use (Ludwig \& Pittman, 1999; Simons et al., 2004), as mentioned above. However, not all of these studies examined the internalization of values from a SDT perspective, and most studies examined prosocial values in isolation of other values. For example, it is possible that when values specific to avoiding drug use are taken into account, prosocial values may no longer be predictive of behaviors outside the prosocial domain.

Academic achievement is another outcome central to adolescence and is associated with positive social skills (Asher \& Coie, 1990), increased life-satisfaction at the transition to college (Salmela-Aro \& Tynkkynen, 2010), and has been shown to serve as a protective factor against smoking and drinking (Piko \& Kovács, 2010), school burnout (Kiuru, Aunola, Nurmi, Leskinen, \& Salema-Aro, 2008), and early sexual activity (Raine et al., 1999) during adolescence. In terms of academic values, when adolescents have internalized academic hopes and ambitions, they are more motivated to achieve academic success within the classroom (Gari \& Kalantzi-Azizi, 1998; Wigfield \& Cambria, 2010). Indeed, adolescents are more likely to persist and succeed in math, English, and science courses in high school when they believe accomplishment in those areas is important (Durik, Vida, \& Eccles, 2006; Simpkins, Davis-Kean, \& Eccles, 2006).

Association with peers also increases during adolescence (Larson \& Richards, 1991), which is salient because deviant peer associations can influence drug use, GPA, and delinquency (Mounts \& Steinberg, 1995). However, when adolescents have internalized religious or prosocial values, they are less likely to associate with deviant peers (Simons et al., 2004), and 
internalized family values can serve as a protective factor against deviant peer associations and subsequent conduct problems during adolescence (Germán, Gonzales, \& Dumka, 2009). Again, we are unaware of studies specifically examining values regarding choosing peers who are a good influence or who are involved in positive behaviors, so the current study will examine associations between values and corresponding behaviors within each of these four domains, as well as between domains, and the role of parenting in the promotion of value-congruent behavior.

\section{Parenting and internalization of values}

Internalization of values is fostered by a variety of socializing agents, but those presumably most active in the process are those agents who have some relationship with the child (Grusec \& Kuczynski, 1997), such as a parent. Parents are particularly effective at fostering internalization of positive values when the relationship is characterized by warmth (Grusec \& Lytton, 1988), mutual compliance (Maccoby \& Martin, 1983), involvement (Grolnick et al., 1997), and accurate perception and acceptance of parental values (Grusec \& Goodnow, 1994; Padilla-Walker, 2007). In opposition, an overemphasis on parental structure, control, and power assertion can diminish feelings of self-generation and internalization as well as long-term compliance with parental expectations (Grolnick et al., 1997; Kuczynski, 1984). While some parental approaches attempting to socialize values are reactive in nature (e.g., disciplining after misbehavior), other parental approaches can be described as proactive (Gardner, Sonuga-Barke, \& Sayal, 1999; Padilla-Walker \& Thompson, 2005), and may be more effective at communicating values than reactive situations where emotional arousal of the child may be high, oftentimes interfering with the parental message (Grusec \& Goodnow, 1994).

Proactive parenting is comprised of practices that involve anticipatory rather than reactive techniques (Goodnow, 1997; Padilla-Walker, Christensen, \& Day, 2011), and focuses on parents' attempts to seek opportunities for behavior instruction before misbehavior has occurred (Holden, 1983; Padilla-Walker \& Thompson, 2005). While proactive parenting of younger children often takes the form of preventative control techniques to encourage compliance (Holden, 1983; Holden \& West, 1989), proactive parenting during late childhood and adolescence more often is an attempt to deal with conflicting values that children may be exposed to from sources outside the home, such as peers and media (Padilla-Walker, 2006; PadillaWalker \& Thompson, 2005). As with other practices, parents use multiple and differing proactive approaches with their adolescents at different times, depending on the context of the situation (Grusec \& Kuczynski, 1997; Padilla-Walker, 2006) and the socialization goal. Indeed, proactive parenting may take the form of active solicitation of information to avoid misbehavior (Kosterman, Hawkins, Guo, Catalano, \& Abbott, 2000; Laird, Marrero, \& Sentse, 2010; Lansford et al., 2006), as well as tactics such as teaching, involvement, prohibition, and redirection of attention (Gardner, Ward, Burton, \& Wilson, 2003; Mounts, 2002; Nikken \& Jansz, 2006).

Although proactive parenting encompasses a variety of parenting behaviors, few researchers have referred to these parental behaviors as "proactive" parenting, resulting in a relatively diverse body of research. However, recent research has begun to examine broad categories of proactive parenting representing parents' attempts to deal with potentially conflicting messages of values, and much of the existing research representing proactive parenting can be subsumed under these three categories. Cocooning is the first broad category of proactive parenting, referring to a parents' attempts to shield their child from outside influences through restricting children's access to situations where they would witness or engage in behavior contrary to parental values (Goodnow, 1997; Padilla-Walker \& Thompson, 2005). Examples of cocooning include complete prohibition of certain media influences (Nathanson, Eveland, Park, \& Paul, 2002; Padilla-Walker \& Coyne, 2011), delinquent activities such as drinking (Keijsers, Frijns, Branje, \& Meeus, 2009; Kim \& Neff, 2010), or of particular friendships (Mounts, 2000). Pre-arming is the second broad category of proactive parenting referring to parents' anticipation that children will encounter conflicting values in their environment and preemptively "arming" children with strategies to face conflicting values when they occur (Goodnow, 1997). Examples of pre-arming include discussing hostility that a child might face due to their race (Barr \& Neville, 2008), explaining why certain peers may be a bad influence (Mounts, 2002), or talking about how portrayals in the media are not realistic (Nathanson, 2001). Deference is the third broad category of proactive parenting, and is often parents' active choice to do nothing preemptively in order to show trust and promote autonomy in their children (Padilla-Walker, 2006; Padilla-Walker \& Thompson, 2005). An example of this may be allowing adolescent children to have unsupervised time with peers, trusting them to stay out of trouble (Borawski, Ievers-Landis, Lovegreen, \& Trapl, 2003; Keijsers et al., 2009). Although deference may sometimes take the form of capitulation to a difficult child or situation, true active deference is often displayed most effectively with older adolescents and only after years of cocooning or pre-arming have laid the foundation of internalization of family values (Padilla-Walker \& Coyne, 2011; Padilla-Walker, Coyne, Fraser, \& Dyer, in press).

Although these specific proactive parenting behaviors are useful, parents rarely use one parenting practice in isolation. As with most parenting practices, parents' proactive attempts are often used flexibly as a function of characteristics of the child, the parent, or the situation (Grusec \& Goodnow, 1994; Grusec \& Kuczynski, 1980). Indeed, research has found that several combinations of proactive parenting practices are used commonly by parents, the most frequent being reasoned cocooning (i.e., where behavior is prohibited, but is coupled with an explanation) and reasoned deference (i.e., where adolescents are allowed to make their own decision with parental input or discussion), and that different combinations of proactive parenting approaches are differentially effective at promoting positive adolescent behaviors (Padilla-Walker et al., 2011). In addition, although the majority of research examining the socialization of values has focused on the direct role of parental autonomy, for example (Niemiec, Ryan, \& Deci, 2010), on adolescents' self-generated values, or has examined values as mediators 
between parenting and adolescents' behavior (Padilla-Walker, 2007; Padilla-Walker \& Carlo, 2007), a person-centered approach to parenting (i.e., examining combinations of proactive parenting using cluster analysis or latent class analysis) lends itself to considering parenting more as an overall climate of the parent-child relationship that may influence the strength of the relation between values and behaviors, rather than a direct socialization practice (Darling \& Steinberg, 1993).

\section{Current study}

Taken together, although research has examined direct relations between proactive parenting and adolescents' behaviors, there is less research examining how different approaches to proactive parenting may differentially promote value-congruent behavior. If proactive parenting is used in an attempt to socialize and teach children family and societal values (Goodnow, 1997; Padilla-Walker \& Thompson, 2005), it would follow that different proactive approaches may create varied socialization environments, some of which may foster value-congruent behavior more effectively than others. Indeed, it is likely that broad approaches to proactive parenting, as assessed using a person-centered approach in the current study, are more indicative of the emotional climate of the family much in the same way as parenting styles, which are thought to have a moderating influence rather than a direct influence on child outcomes (Darling \& Steinberg, 1993). Thus, the purpose of the current study was two-fold. First, using a longitudinal approach, we sought to understand how value-congruent behavior in four domains (drugs, prosocial, school, friends) was moderated by proactive parenting, or how the strength of the association between values and corresponding behaviors might differ as a function of proactive parenting (see Fig. 1). This was assessed by using cluster analysis to determine the combinations of proactive parenting used by parents (Padilla-Walker et al., 2011), and then conducting a number of simultaneous multiple group path analysis using structural equation modeling. Based on SDT's emphasis on parental autonomy granting when fostering self-generated values and behaviors (Niemiec et al., 2010), we hypothesized that adolescents would display more consistent value-congruent behavior with parental approaches that included pre-arming (which communicates parental values) and deference (which allows for autonomy), but not in proactive attempts that included solely cocooning (which is more controlling).

Second, based on research suggesting numerous relations between values and behaviors in non-corresponding domains (e.g., Laible et al., 2004; Piko \& Kovács, 2010; Tarry \& Emler, 2007), the current study sought to understand if internalization of values in one domain was related to behavior in another domain, and whether this was moderated by proactive parenting. Because most studies examine values in isolation of one another, it is unclear if value-congruent behavior is the norm, or if values in particular domains are strongly related to multiple behaviors. Given the dearth of research on how adolescents' values in one domain may influence behaviors in another domain, and how these relations might be impacted by proactive parenting, we had no specific hypotheses in this regard.

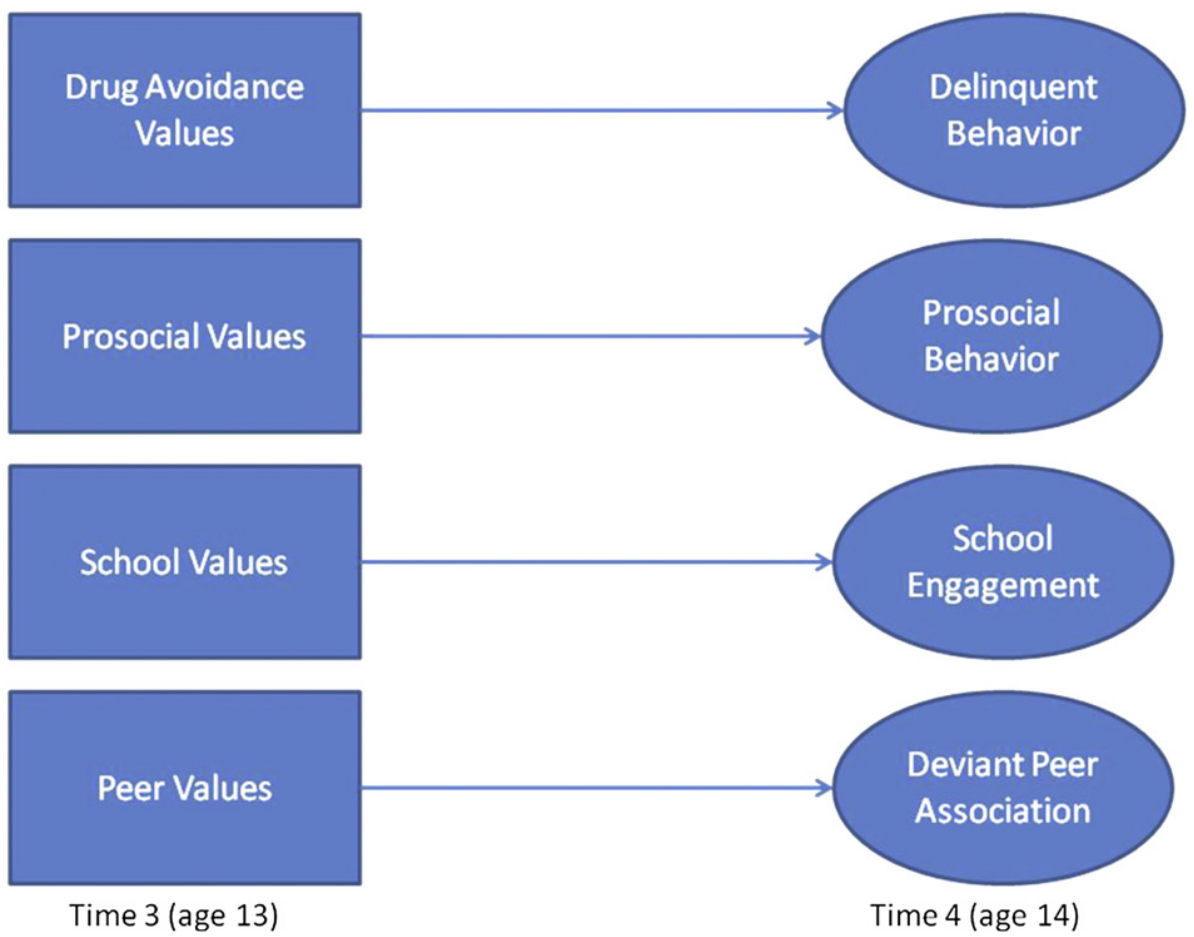

Fig. 1. Theoretical path model of value-congruent behaviors in four domains. Note: First purpose of the study was to examine whether the above paths (valuecongruent behaviors) differed in strength as a function of proactive parenting strategy. Second purpose of the study was to examine whether paths from each value to all four behaviors were significant and differed in strength as a function of proactive parenting strategy. 


\section{Method}

\section{Participants}

The participants for this study were taken from Waves 2, 3 and 4 of the Flourishing Families Project (FFP), which is a longitudinal study of inner-family life (all waves were approximately 1 year apart) Wave 1 was not used because measures were not available. The current sample consisted of 335 two-parent families with a child between the ages of 11 and 14 at Time 2 ( $M$ age of child $=12.28, \mathrm{SD}=.99,51 \%$ female), $94 \%$ of which had complete data at Time 4 ( $M$ age of child $=14.32$, $\mathrm{SD}=.98$ ). Seventy-three percent of fathers, $86 \%$ of mothers, and $80 \%$ of children were European American, $18 \%$ of fathers, $8 \%$ of mothers, and 3\% of children were African American, and $9 \%$ of fathers, $6 \%$ of mothers, and $17 \%$ of children were from other ethnic groups or were multiethnic. Fourteen percent of families made less than $\$ 25,000$ per year, $16 \%$ made between $\$ 25,000$ and $\$ 50,000$ a year, and $70 \%$ made more than $\$ 50,000$ per year; with $21 \%$ of mothers and $5 \%$ of fathers reporting being unemployed.

\section{Procedure}

Participant families for the [project name masked FFP for blind review] were selected from a Northwestern city in the United States and were interviewed during the first eight months of 2007 for Time 1. At Time 1, all families were contacted directly using a multi-stage recruitment protocol. Of the 692 eligible families contacted, 423 agreed to participate, resulting in a 61\% response rate. For more information regarding participant selection, please see (Padilla-Walker, Harper, \& Bean, 2011). At each wave of data collection, interviewers visited the family's home and conducted an assessment interview that included video-taped interactions (not used in current study), as well as questionnaires that were completed in the home (participants were encouraged to complete questionnaires in separate rooms and not to discuss answers during administration). Both parents and children completed informed consent documents at the start of each in-home visit, and the project was approved by the institutional review board at the university from which the research originated. The most frequent reasons cited by families for not wanting to participate in the study were lack of time and concerns about privacy. It is important to note that there were very few missing data at either time point. As interviewers collected each segment of the in-home interview, questionnaires were screened for missing answers and double marking.

\section{Measures}

\section{Proactive parenting}

Mothers and fathers responded to nine items at Time 2 on a 5-point Likert scale ranging from 1 (never) to 5 (always) to assess three types of proactive parenting practices found in previous studies: cocooning, pre-arming, and deference. This scale has been used on adolescent populations in the past and has been found to be reliable and valid (Padilla-Walker, 2006; Padilla-Walker \& Thompson, 2005). Parents were asked to think of how frequently they used a variety of intentional and active approaches to socialize their children before transgression has occurred. Sample items for cocooning (three, $\alpha=.77$ for mothers, .72 for fathers), pre-arming (three items, $\alpha=.75$ for mothers, .79 for fathers) and deference (three items, $\alpha=.70$ for mothers, .65 for fathers) include, "How often do you shelter your child from influences that might be negative in order to avoid misbehavior before it occurs?", "How often do you talk to your child about rules in order to avoid misbehavior before it occurs?," and "How often do you allow your child to be exposed to influences that might be negative because you want your child to know that you trust their choices?" respectively.

\section{Internalization of values}

Internalization of values was measured at Time 3 with 20 items adapted from the Prosocial Self-Regulation Questionnaire used by Ryan and Connell (1989). Adolescents were asked to rate the importance of four different reasons why they might or might not engage in a certain behavior, including avoiding drug use (4 items), engaging in prosocial behavior ( 8 items that were combined: 4 representing kindness and 4 honesty), doing well in school (4 items), and choosing good friends ( 4 items), on a scale from 1 (not at all important) to 5 (very important). Of the four items for each domain, there was one for each of the four forms of values regulation posited by Deci and Ryan (1991), including external (e.g., "I try to avoid drinking, drugs, smoking, etc. because I will get in trouble if I do any of those things."), introjected (e.g., I try to be honest because my parents will be disappointed if I am not honest."), identified (e.g., "I choose good friends because I think it's important to have friends who are a good influence."), and integrated (e.g., "I try to do well in school because I enjoy doing my school work.").

Composite scores for each domain or type of value were created by differentially weighting individual scores on the four levels ( -2 for external, -1 for introjected, +1 for identified, and +2 for integrated), as done by Grolnick and Ryan (1989). This relative autonomy composite indicates the degree to which adolescents prefer using more internalized regulation (identified and integrated) as compared to less internalized regulation (external and introjected). Although the items used in the present study have not all been used previously, the general measurement format has demonstrated adequate reliability and validity in prior studies (Grolnick \& Ryan, 1989; Ryan \& Connell, 1989). Although only composite scores were used, the current items 
displayed adequate reliability when calculated across domains as 5-item scales representing external $(\alpha=.70)$, introjected $(\alpha=.77)$, identified $(\alpha=.74)$, and integrated $(\alpha=.67)$ regulation.

Delinquency

Adolescents' delinquent behaviors were assessed at Time 4 using mother $(\alpha=.77)$, father $(\alpha=.66)$, and child $(\alpha=.77)$ reports of 9 items regarding antisocial behaviors (Barber, Stolz, Olsen, \& Maughn, 2005). Sample items include "I (my child) uses alcohol or drugs," and "I (my child) smokes cigarettes or chews tobacco" and were assessed on a scale ranging from 0 (not true) to 2 (very true or often true). A latent variable was created for delinquency using mean scale scores reported by mother, father, and child reports.

\section{Prosocial behavior}

Adolescents' prosocial behavior toward family members was measured at Time 4 using mother, father, and child-report of 9 items adapted from the Kindness and Generosity (Peterson \& Seligman, 2004). The original measure was designed to assess behavior toward strangers, and the current study adapted these items to target prosocial behavior toward family members ("I (my child) really enjoy(s) doing small favors for my family") on a 5-point Likert scale ranging from 1 (not like me/my child at all) to 5 (very much like me/my child). Mothers $(\alpha=.90)$, fathers $(\alpha=.91)$, and adolescents $(\alpha=.91)$ reported on the adolescents' prosocial behavior toward family members, and mean scale scores were used to create a latent variable representing prosocial behavior toward family.

\section{School engagement}

Adolescents' level of emotional and behavioral functioning at school was assessed at Time 4 using mother $(\alpha=.88)$, father $(\alpha=.89)$, and child $(\alpha=.85)$ reports of the School Engagement Scale (Fredericks, Blumenfeld, \& Paris, 2004). Respondents were asked the degree to which they agreed or disagreed with items such as "I (my child) pay attention in class" and "I (my child) feel support from my teachers at school." Responses ranged from 1 (strongly disagree) to 5 (strongly agree). A latent variable was created for school engagement using mean scale scores of mother, father and child reports.

\section{Deviant peer association}

Association with deviant peers was assessed using 11 items adapted from Elliott, Huizinga, and Ageton (1985). Adolescents reported on how many of their friends participated in delinquent behaviors such as "Purposely damage or destroy property" and "Get in fights at school." Responses ranged on a 5-point Likert scale ranging from 1 (none of my friends) to 5 (all of my friends), with higher scores indicating higher levels of deviant peer association $(\alpha=.87)$.

\section{Results}

\section{Descriptive statistics and correlations}

$T$-tests were conducted to determine if proactive parenting practices varied as a function of parent gender, and revealed that there were no significant differences between mothers' $(M=2.75, \mathrm{SD}=.86)$ and fathers' $(M=2.66, \mathrm{SD}=.81)$ cocooning $(r=.36, p<.001)$ or mothers' $(M=3.04, \mathrm{SD}=.74)$ and fathers' $(M=3.08, \mathrm{SD}=.69)$ deference $(r=.41, p<.001)$, but mothers $(M=3.44, \mathrm{SD}=.81)$ reported using pre-arming more than did fathers $(M=3.27, \mathrm{SD}=.85 ; r=.19, p<.01), t(305)=2.82$, $p<.01$. Means, standard deviations, ranges, and correlations for all study variables are presented in Table 1 . It should be noted that values in all domains were significantly associated with their corresponding behaviors, and in many cases, values were as strongly or more strongly related to behaviors outside their domain as those within their domain, especially school values. It should also be noted that all four values were significantly associated with one another.

\section{Cluster analysis}

Ward's hierarchical clustering procedure was conducted on the three proactive parenting practices (cocooning, prearming, and deference), separately for mothers and fathers. Using the hierarchical approach in an attempt to maximize the differences between clusters, we determined the number of clusters by treating each parent as a separate cluster and then combining the most similar parents systematically until there was one, all-inclusive cluster (Ward, 1963). In order to determine the number of clusters, first we examined hierarchical dendrogram and agglomeration coefficients (Bergman, Magnusson, \& El-Khouri, 2003). Dendrograms revealed that there were between 3 and 4 clusters for both mothers and fathers. When examining agglomeration coefficients, the number of clusters is determined based on the relative stability in change in the agglomeration coefficient from one stage to the next (Hair, Anderson, Tatham, \& Black, 1998). This examination supported a 3-cluster solution for mothers and a 4-cluster solution for fathers. Finally, conceptually the 3-cluster solution for mothers was consistent with past research and had appropriate numbers of mothers per cluster, whereas the 4-cluster solution for mothers resulted in a fourth group that was not meaningfully different and was very small in size. For fathers, the 4-cluster solution was the most conceptually and statistically sound.

When comparing mothers' and fathers' cluster solutions, three very similar clusters emerged for both parents. Cluster $1(n$ mother $=38,12 \%$; $n$ father $=84,28 \%)$ consisted of parents who reported moderate levels of cocooning $(z$ mother $=-.38, z$ 
Table 1

Means, standard deviations, and correlations between values and behaviors

\begin{tabular}{|c|c|c|c|c|c|c|c|c|c|c|c|c|c|c|}
\hline & 1 & 2 & 3 & 4 & 5 & 6 & 7 & 8 & 9 & 10 & 11 & 12 & 13 & 14 \\
\hline 1. Drug values CR & - & & & & & & & & & & & & & \\
\hline 2. Prosocial values CR & $.35^{* * *}$ & - & & & & & & & & & & & & \\
\hline 3. School values CR & $.25^{* * *}$ & $.51^{* * *}$ & - & & & & & & & & & & & \\
\hline 4. Friend values $C R$ & $.33^{* * *}$ & $.52^{* * *}$ & $.40^{* * *}$ & - & & & & & & & & & & \\
\hline 5. Delinquency MR & $-.25^{* * *}$ & $-.19^{* *}$ & $-.26^{* * *}$ & $-.14^{*}$ & - & & & & & & & & & \\
\hline 6. Delinquency FR & $-.22^{* * *}$ & -.12 & $-.24^{* * *}$ & -.08 & $.70^{* * *}$ & - & & & & & & & & \\
\hline 7. Delinquency CR & $-.32^{* * *}$ & $-.19^{* *}$ & $-.26^{* * *}$ & $-.15^{*}$ & $.49^{* * *}$ & $.56^{* * *}$ & - & & & & & & & \\
\hline 8. Prosocial beh MR & .02 & $.14^{*}$ & $.20^{* * *}$ & .03 & $-.27^{* * *}$ & $-.26^{* * *}$ & $-.19^{* *}$ & - & & & & & & \\
\hline 9. Prosocial beh FR & .03 & $.22^{* * *}$ & $.22^{* * *}$ & .08 & $-.26^{* * *}$ & $-.34^{* * *}$ & $-.16^{* *}$ & $.67^{* * *}$ & - & & & & & \\
\hline 10. Prosocial beh CR & .06 & $.26^{* * *}$ & $.33^{* * *}$ & $.12^{*}$ & $-.15^{* *}$ & $-.13^{*}$ & $-.24^{* * *}$ & $.45^{* * *}$ & $.38^{* * *}$ & - & & & & \\
\hline 11. School eng MR & $.14^{*}$ & $.15^{* *}$ & $.36^{* * *}$ & $.15^{*}$ & $-.48^{* * *}$ & $-.50^{* * *}$ & $-.35^{* * *}$ & $.35^{* * *}$ & $.28^{* * *}$ & $.27^{* * *}$ & - & & & \\
\hline 12. School eng FR & $.15^{*}$ & $.20^{* *}$ & $.38^{* * *}$ & $.15^{*}$ & $-.41^{* * *}$ & $-.55^{* * *}$ & $-.30^{* * *}$ & $.37^{* * *}$ & $.48^{* * *}$ & $.25^{* * *}$ & $.76^{* * *}$ & - & & \\
\hline 13. School eng CR & $.25^{* * *}$ & $.23^{* * *}$ & $.48^{* * *}$ & $.17^{* *}$ & $-.38^{* * *}$ & $-.39 * * *$ & $-.44^{* * *}$ & $.28^{* * *}$ & $.24^{* * *}$ & $.48^{* * *}$ & $.61^{* * *}$ & $.57^{* * *}$ & - & \\
\hline $\begin{array}{l}\text { 14. Deviant Peer } \\
\text { Association CR }\end{array}$ & $-.30^{* * *}$ & $-.24^{* * *}$ & $-.34^{* * *}$ & $-.27^{* * *}$ & $.34^{* * * *}$ & $.39^{* * *}$ & $.67^{* * *}$ & $-.17^{* *}$ & $-.14^{*}$ & $-.28^{* * *}$ & $-.37^{* * *}$ & $-.26^{* * *}$ & $-.46^{* * *}$ & - \\
\hline Mean & .35 & 3.02 & 1.99 & 1.48 & .10 & .11 & .19 & 3.29 & 3.41 & 3.93 & 3.74 & 3.71 & 3.64 & 1.39 \\
\hline SD & 2.67 & 2.32 & 3.39 & 2.37 & .17 & .17 & .24 & .83 & .85 & .79 & .68 & .70 & .61 & .50 \\
\hline Range & $-9.0-9.0$ & $-3.5-9.0$ & $-9.0-9.0$ & $-7.0-9.0$ & $0-1.33$ & $0-1.22$ & $0-1.44$ & $1.56-4.67$ & $1.22-5.0$ & $1.0-5.0$ & $1.38-5.0$ & $1.88-5.0$ & $2.0-5.0$ & $1.0-3.82$ \\
\hline
\end{tabular}

Note: $\mathrm{CR}=$ child report, $\mathrm{MR}=$ mother report, $\mathrm{FR}=$ father report.

${ }^{*} p<.05,{ }^{* *} p<.01,{ }^{* * *} p<.001$.

father $=.16)$ and low levels of pre-arming $(z$ mother $=-1.16, z$ father $=-.76)$, and deference $(z$ mother $=-1.19, z$ father $=-.44)$. This cluster will be referred to as Cocooning Parents because of the three practices, cocooning seemed to be the most central. Cluster 2 ( $n$ mother $=167,53 \%$; $n$ father $=58,18 \%)$ consisted of parents who reported relatively high levels of deference $(z$ mother $=.63, z$ father $=.68)$, but moderate to low levels of pre-arming $(z$ mother $=-.26, z$ father $=-1.14)$ and cocooning $(z$ mother $=-.54, z$ father $=-1.04)$. This cluster will be referred to as Actively Deferring Parents because for these parents, the decision to act in a deferring manner was an active choice of how to respond before misbehavior occurred. Cluster 3 ( $n$ mother $=113,36 \%$; $n$ father $=101,33 \%)$ consisted of parents who reported relatively low levels of deference $(z$ mother $=-.54, z$ father $=-.52)$, but moderate to high levels of pre-arming $(z$ mother $=.78, z$ father $=.75)$ and cocooning $(z$ mother $=.92, z$ father $=.88$ ). This cluster will be referred to as Reasoned Cocooning Parents because these parents largely sheltered their children from conflicting influences even before misbehavior occurred, but provided reasoning for those decisions.

For fathers only, a fourth cluster emerged $(n$ father $=65,21 \%$ ) and consisted of parents who reported relatively low levels of cocooning ( $z$ father $=-.67$ ), but moderate to high levels of pre-arming ( $z$ father $=.76$ ) and deference $(z$ father $=.82$ ). This cluster will be referred to as Reasoned Deferring Parents because these parents (fathers) balanced discussing concerns with their child with trusting the child to make independent decisions before misbehavior occurred.

\section{Proactive parenting as a moderator of value-congruent behavior}

In order to assess the moderating role of proactive parenting, models were estimated using Analysis of Moments Structure (AMOS) software (Arbuckle, 2010). First a measurement model was estimated with all latent outcome variables (delinquency, prosocial behavior, and school engagement) and yielded acceptable fit, $X^{2}(16)=47.047, p<.001, \mathrm{CFI}=.980$, RMSEA $=.064$, with all factor loadings on latent variables statistically significant with values ranging from .54 to .93 . Next, structural models were estimated (separately for mother and father) modeling the four types of values at Time 3 (drugs, prosocial, school, and friends) as predictors of their corresponding behaviors at Time 4 (delinquency, prosocial behavior, school engagement, and deviant peer association). In addition, structural paths were estimated from each value to all behavioral outcomes across domains (all direct paths). Gender was used as a control variable in all models but did not impact results, so it was left out for parsimony. To test for group differences as a function of proactive parenting cluster at Time 2, a multi-group model was estimated and compared using a $X^{2}$ difference test. This approach assesses moderation of strength (Bentler, 1995; Garcia \& Kandemir, 2006; Sharma, Durand, \& Gur-Arie, 1981), which assesses the strength of the relation between the predictors and criterion variable, and how this might differ across levels of a qualitative variable (in this case, proactive parenting strategy). Moderation of strength is best modeled using multiple group analyses, which in the current study was achieved by conducting a multiple group simultaneous path analysis (see Fig. 1).

For mothers, constraining one path at a time revealed that constraining three paths to be equal across clusters resulted in a decrease in model fit (the path from drug avoidance values to delinquency, the path from prosocial values to delinquency, and the path from friend values to delinquency), so these three paths were left free to vary across clusters, and all others were constrained to be equal across clusters. It should be noted that only one of the paths left free to vary represented a valuecongruent behavior, the path from drug avoidance values to delinquency. This final model yielded acceptable fit $\left(X^{2}\right.$ $(132)=223.566, p<.001 ; \mathrm{CFI}=.954, \mathrm{TLI}=.91, \mathrm{RMSEA}=.041)$. For cocooning mothers, $\operatorname{drug}$ avoidance values $(\beta=-.57, p<.001)$ and prosocial values $(\beta=-.39, p<.05)$ were significantly related to delinquency; and drug avoidance values were significantly 
related to deviant peer association $(\beta=-.30, p<.05)$. For actively deferring mothers, drug avoidance values were associated with delinquency $(\beta=-.35, p<.001)$, prosocial values were associated with prosocial behaviors $(\beta=.19, p<.05)$, school values were associated with school engagement $(\beta=.43, p<.001)$, and friend values $(\beta=-.15, p<.05)$ were associated with deviant peer association. For reasoned cocooning mothers, school values were significantly related to school engagement $(\beta=.59$, $p<.001)$, delinquency $(\beta=-.36, p<.001)$, prosocial behavior $(\beta=.37, p<.01)$, and deviant peer association $(\beta=-.30, p<.01)$.

For fathers, constraining one path at a time revealed that constraining six of the paths to be equal across clusters resulted in a decrease in model fit (the path from prosocial values to prosocial behavior, the path from drug avoidance values to prosocial behavior, the path from drug avoidance values to school engagement, the path from prosocial values to school engagement, the path from prosocial values to deviant peer association, the path from school values to delinquency), so these six paths were left free to vary across clusters, and all others were constrained to be equal across clusters. It should be noted that only one of the paths left free to vary represented a value-congruent behavior. This final model yielded acceptable fit $\left(X^{2}(176)=253.049\right.$, $p<.001 ; \mathrm{CFI}=.953$, TLI $=.90$, RMSEA $=.037)$. For all four clusters, drug avoidance values were related to delinquency $(b=-.014, \beta$ range from -.24 to $-.35, p<.001)$, school values were related to school engagement $(b=.073, \beta$ range from .42 to $.49, p<.001)$ and prosocial behavior $(b=.048, \beta$ range from .20 to $.30, p<.001)$; and friend $(b=-.025, \beta$ range from -.12 to $-.13, p<.05)$, and drug avoidance $(b=-.025, \beta$ range from -.12 to $-.17, p<.01)$ values were related to deviant peer association. For those paths that were free to vary across clusters, for all fathers except reasoned deferring fathers, school values were related to delinquency ( $\beta$ ranged from -.26 to $-.32, p<.05$ ). For cocooning fathers, school values were also related to deviant peer association $(\beta=-.34, p<.001)$. For reasoned cocooning fathers, drug avoidance values were related to school engagement $(\beta=.35, p<.001)$ and school values were related to delinquency $(\beta=-.32, p<.001)$ and deviant peer association $(\beta=-.37, p<.001)$. For reasoned deferring fathers, prosocial values were related to prosocial behavior $(\beta=.32, p<.05)$.

\section{Discussion}

The current study sought to examine the moderating role of proactive parenting on adolescents' value-congruent behaviors in four different domains: drug use, prosocial behavior, school, and friends. Based on Self-Determination Theory (SDT), it was hypothesized that proactive approaches using both autonomy and communication would lead to the most consistent value-congruent behaviors (Knafo \& Assor, 2007) because these practices would be more likely to promote feelings of self-generation (Deci \& Ryan, 2000; Niemiec et al., 2010). In general, findings were only partially consistent with hypotheses. More specifically, maternal use of active deference and paternal use of reasoned deference were the only approaches the resulted in significant value-congruent behaviors in all four domains, but moderation analyses were not always statistically significant. The current study also sought to explore the moderating role of proactive parenting in relation to congruence between adolescents' values and behaviors in different domains. Findings suggested a number of associations between values and behaviors in different domains, and found that proactive parenting moderated these paths in several cases, suggesting that the over-arching emotional climate of the parent-child relationship is an important variable to consider when examining the associations between adolescents' values and behaviors (Darling \& Steinberg, 1993).

\section{Value-congruent behaviors}

Consistent with past research (Grusec \& Kuczynski, 1980; Padilla-Walker et al., 2011), the current study suggested that mothers and fathers displayed flexibility in their proactive parenting, with results revealing parents who took different approaches to proactive parenting, including cocooning, deferring, reasoned cocooning, and reasoned deferring parents. These findings suggest utility in continuing to examine proactive parenting from a person-centered approach which allows for examining parenting in more nuanced detail rather than exploring practices in isolation of one another (Grusec \& Goodnow, 1994). While past research suggests that proactive parenting is related to numerous positive outcomes in children and adolescents (Mounts, 2002; Nathanson, 1999), the current study added to this body of research by suggesting that broad approaches to proactive parenting may be indicative of family environments or climates that differentially foster values-congruent behaviors (Darling \& Steinberg, 1993).

For maternal parenting, while all three proactive approaches revealed associations between values and behaviors, the only proactive approach that displayed value-congruent behavior in all four domains was active deference (which was also notably the largest maternal cluster). These findings are consistent with SDT's emphasis on parental autonomy granting as a means whereby parents can foster adolescents' self-generated behaviors, and suggests that even a general family climate of autonomy (as compared to specific parenting strategies that promote autonomy and are directly related to self-generated values) might influence internalization of values (Niemiec et al., 2010). While studies have suggested that during early adolescence deference may not be an appropriate proactive strategy to use in isolation (Padilla-Walker et al., 2011), these findings suggest that as children reach mid-adolescence, allowing them to make their own decisions may result in numerous positive outcomes (Deci \& Ryan, 2000; Silk, Morris, Kanaya, \& Steinberg, 2003). In-depth interviews with parents suggest that parental deference is often used during adolescence after parents feel they have adequately communicated family values (either via pre-arming or cocooning) when their child was younger (Denham et al., 2000; Padilla-Walker \& Thompson, 2005), and that deference is now the parent's attempt to display trust in their child. Parents who use active deference by no means feel uninvolved in their adolescent's life, but rather, purport that if they see behavior influenced by conflicting values they will intervene, but until that point, they will allow autonomy (Padilla-Walker, 2006). 
In terms of paternal parenting, the only proactive approach that displayed value-congruent behavior in the prosocial domain (as well as the other three) was reasoned deference. These findings further support the importance of parental autonomy granting in the promotion of value-congruent behaviors (Deci \& Ryan, 2000), and also suggest the importance of parental communication of values (Milevsky, Szuchman, \& Milevsky, 2008), which likely promotes prerequisites to internalization such as accurate perception of parental values (Grusec \& Goodnow, 1994; Padilla-Walker, 2007). It is not clear why fathers' use of reasoned deference was more salient, while mothers' use of deference (without reasoning) seemed to be most effective, but future research should continue to examine the differences between maternal and paternal proactive parenting, and how parent and child gender might be associated with effectiveness of parenting strategy. Taken together, these findings have implications for our understanding of the role of parenting on adolescents' internalization of values, and suggest utility in not only examining direct and indirect associations between parenting and adolescent outcomes, but also examining the broader family climate or environment (e.g., controlling vs. autonomy granting) as an important moderating influence between children's own characteristics (e.g., values) and their subsequent behaviors (Darling \& Steinberg, 1993).

\section{Values promoting behaviors across domains}

Although many studies examine value-congruent behavior within a single domain, research suggests that values also influence behavior across domains (e.g., Bardi \& Schwartz, 2002), suggesting that some values might have further reaching impact than others. Indeed, a careful examination of bivariate correlations in the current study suggested that all values were significantly associated with their corresponding behaviors, but were also often correlated at similar levels with behaviors outside of their domain. In addition, values related to doing well in school appeared to be the most consistently associated with behaviors in all four domains, suggesting a potential fruitful avenue for future research and implications for parents and educators regarding the importance of socializing values related to academic achievement.

In terms of the role of parenting on the relations between values and behaviors, although in the current study some form of deference was the parental approach resulting in the most consistent value-congruent behaviors, other proactive approaches moderated the associations between values and behaviors across domains more often than they did value-congruent behaviors. Namely, mothers and fathers who used predominantly cocooning had children whose values were primarily associated with delinquency and deviant peer association. It is possible that parents who shield their children from negative influences might also focus on helping their children to avoid situations that might involve risk, such as delinquency and association with deviant peers (Pratt, Hunsberger, Pancer, \& Alisat, 2003). Future research should examine the specific values that are communicated and the messages that are received during interactions that involve parental cocooning. Indeed, if these parents are focusing on avoidance of misbehavior (rather than the encouragement of positive behavior), adolescents may develop value systems where multiple domains of values all contribute to one's avoidance of negative behaviors and situations, to the detriment of the development of positive value-behavior congruence.

Further, reasoned cocooning mothers and cocooning and reasoned cocooning fathers (notably the largest paternal cluster) had children whose school values were associated with school engagement, but were also associated with many of the other adolescent behaviors. Again, it is possible that parents who use higher levels of control (perhaps combined with discussion) in proactive strategies may also have high expectations for their children, especially in the domain of scholastic competence. Because these associations held across both parents, suggesting a meaningful pattern as a function of restrictive and communicative proactive parenting, it would be interesting for future research to examine the types of values that are promoted by parents who take different proactive approaches to determine whether parents who share particular values also approach proactive parenting in a similar fashion, or whether moderately controlling parenting is merely associated with the avoidance of misbehavior and encouragement of scholastic competence, regardless of parental values. These findings may have implications for character education programs and intervention programs that focus on parent-child relationships and children's internalization of positive values. If future research can more clearly understand the types of values (if any) being communicated by parents who take different proactive approaches, it might be possible to help parents communicate their values in a more effective way or to suggest strategies for parents or educators who might want to promote a particular behavior (e.g., academic achievement) in their child. Given that parenting was not always moderating these associations, it will also be important for future research to more carefully examine the development of values internalization and the role of other socialization sources (e.g., peers, media), in addition to the values held by the larger culture.

\section{Limitations and conclusions}

The current study was not without limitations. Namely, despite the longitudinal design of the current study, the nature of the data precludes causal inferences. In addition, because of the desire to include fathers, the current study focused solely on two-parent families, and is thus not generalizable to all family types. It will be important for future research to examine how proactive parenting might differ in single-parent or divorced families, as well as low-income and ethnically diverse families, and how this might influence value-congruent behaviors. Research suggests that minority parents use a great deal of proactive parenting in their attempts to prepare their children for inevitable discrimination (Barr \& Neville, 2008; Harrison, Wilson, Pine, \& Chan, 1990), so this is a fruitful area for future research. In addition, although using multiple reporters of child behavior was a strength of the current study, future research should also consider including teacher reports or observational data of behavior where relevant, in an attempt to provide another perspective outside of the family. Further, although 
patterns differed as a function of proactive parenting cluster, these differences were not always statistically significantly different as a function of cluster, suggesting a lack of moderation for some instances of value-congruent behaviors. It is possible that this is an issue of lack of power given the person-centered approach, which should be examined in future research. It is also possible that any proactive approach is effective at promoting value-congruent behavior in some domains, which may be a function of additional socialization influences outside the family that promote similar values. Indeed, proactive parenting more often moderated the link between values and behaviors in different domains, suggesting that perhaps value-congruent behavior is already established by this developmental age, and that parental approaches to the socialization of values during adolescence is more likely to result in congruence between values and a variety of other behaviors that may be salient during this time period. Future research should more carefully examine this possibility. Finally, in the current study proactive parenting was measured broadly, and the person-centered approach likely taps more into the over-arching climate of proactive parenting than it does specific practices in specific situations (Darling \& Steinberg, 1993). Indeed, research on proactive parenting that is specific to peer (Mounts, 2002) or media influences (Nathanson, 1999) may find that proactive parenting practices operate differently as a function of context, and are more directly related to children's behaviors. So although proactive parenting as conceptualized broadly in the current study provides a helpful framework for organizing a variety of literatures, additional research is needed on the specific practices parents use, the form that these practices take (e.g., does pre-arming take the form of discussion, derogatory comments about the values of another, etc), and how these forms may vary as a function of context (e.g., peers vs. media).

Despite these limitations, the current study makes a number of important contributions to the current literature on the internalization of values. First, findings suggest that although proactive approaches, including pre-arming and cocooning, may be effective earlier in adolescence (Padilla-Walker et al., 2011), that parents who allow increased autonomy as their children get older have adolescents with more consistent value-congruent behavior. Given that values are only valuable as socialization tools inasmuch as they are reflected in behaviors, while parents may believe that sheltering their child is the best way to protect them from conflicting messages of values, findings did not support this. It is important to note that although it could not be determined in the current study, it is likely that deference is effective because of the developmental appropriateness of this approach for this age group, and that parents are most effective when they use the appropriate levels of control and autonomy as their children develop, potentially using higher levels of cocooning and especially pre-arming while children are younger, and less so as they get older (Padilla-Walker et al., in press).

Second, the current study contributed significantly to our understanding of the associations between values and behaviors in different domains, suggesting that these associations are moderated by parents' proactive approach. Indeed, the current findings raised the possibility that depending on what values and behaviors are emphasized through each proactive approach, various values may all be associated with a particular behavior, or a specific value may be associated with a wide variety of behaviors. Although parents likely communicate values in a variety of ways, it is possible that parents who feel strongly about particular values may stress those values to the extent that they are reflected both in behaviors within and outside of their respective domain. For example, if a particular family greatly values education, and teaches and socializes this in their children, those children might make numerous choices (e.g., who to spend time with, whether or not to engage in behavior that might jeopardize their future) based on their desire to do well in school. This may be particularly salient as a function of the content of parent-child conversations surrounding values, which is a fruitful area for future research.

\section{Acknowledgments}

We thank the Family Studies Center at BYU, the School of Family Life, and the College of Family Home and Social Science at BYU, and we recognize the generous support of the many private donors who provided support for this project. We also thank those families who were willing to spend valuable hours with our team in interviews, and the many students who assisted in conducting the interviews.

\section{References}

Allen, J. P., Leadbeater, B. J., \& Aber, J. L. (1990). The relationship of adolescents' expectations and values to delinquency, hard drug use, and unprotected sexual intercourse. Development and Psychopathology, 2(1), 85-98.

Arbuckle, J. L. (2010). Amos 19.0 user's guide. Chicago, IL: SPSS, Amos Development Corporation.

Asher, S. R., \& Coie, J. D. (Eds.). (1990). Peer rejection in childhood. Cambridge, England: University Press.

Bandura, A., Caprara, G. V., Barbaranelli, C., Pastorelli, C., \& Regalia, C. (2001). Sociocognitive self-regulatory mechanisms governing transgressive behavior. Journal of Personality and Social Psychology, 80, 125-135.

Barber, B. K., Stolz, H. E., Olsen, J. A., \& Maughn, S. L. (2005). Parental support, psychological control, and behavioral control: assessing relevance across time, culture, and method. Monographs of the Society for Research in Child Development, 70(4).

Bardi, A., \& Schwartz, S. H. (2002). Values and behavior: strength and structure of relations. Personality and Social Psychology Bulletin, 29, 1207-1220.

Barr, S. C., \& Neville, H. A. (2008). Examination of the link between parental racial socialization messages and racial ideology among Black college students. Journal of Black Psychology, 34(2), 131-155.

Bentler, P. M. (1995). EQS structural equations program manual. Encino, CA: Multivariate Software.

Bergman, L. R., Magnusson, D., \& El-Khouri, B. M. (2003). Studying individual development in an interindividual context: A person-oriented approach. Mahwah, NJ: Lawrence Erlbaum.

Borawski, E. A., Ievers-Landis, C. E., Lovegreen, L. D., \& Trapl, E. S. (2003). Parental monitoring, negotiated unsupervised time, and parental trust: the role of perceived parenting practices in adolescent health risk behaviors. Journal of Adolescent Health, 33(2), 60-70.

Carlo, G., Eisenberg, N., \& Knight, G. P. (1992). An objective measure of adolescents' prosocial moral reasoning. Journal of Research on Adolescence, 2, 331-349. 
Darling, N., \& Steinberg, L. (1993). Parenting style as context: an integrative model. Psychological Bulletin, 113(3), 487-496.

Deci, E. L., \& Ryan, R. M. (1991). A motivational approach to self: integration in personality. In R. A. Dienstbier (Ed.), Nebraska symposium on motivation, 1990: Perspectives on motivation (pp. 237-288). Lincoln, NE US: University of Nebraska Press.

Deci, E. L., \& Ryan, R. M. (2000). The "what" and "why" of goal pursuits: human needs and the self-determination of behaivor. Psychological Inquiry, 11, 227-268.

Diener, M. L., \& Kim, D. Y. (2004). Maternal and child predictors of preschool children's social competence. Applied Developmental Psychology, 25, 3-4.

Denham, S. A., Workman, E., Cole, P. M., Weissbrod, C., Kendziora, K. T., \& Zahn-Waxler, C. (2000). Prediction of externalizing behavior problems from early to middle childhood: the role of parental socialization and emotion expression. Development and Psychopathology, 12(1), 23-45.

Durik, A. M., Vida, M., \& Eccles, J. S. (2006). Task values and ability beliefs as predictors of high school literacy choices: a developmental analysis. Journal of Educational Psychology, 98, 382-393.

Eisenberg, N., Fabes, R. A., Karbon, M., Murphy, B. C., Wosinski, M., Polazzi, L., et al. (1996). The relations of children's dispositional prosocial behavior in emotionality, regulation, and social functioning. Child Development, 67, 974-992.

Elliott, D. S., Huizinga, D., \& Ageton, S. (1985). Explaining delinquency and drug use. Beverly Hills, CA: Sage.

Erikson, E. H. (1968). Identity: Youth and crisis. New York: Norton.

Fredericks, J. A., Blumenfeld, P. C., \& Paris, A. H. (2004). School engagement: potential of the concept, state of the evidence. Review of Educational Research, 74, 59-109.

Garcia, R., \& Kandemir, D. (2006). An illustration of modeling moderating variables in cross-national studies. International Marketing Review, 23, 371-389.

Gardner, F., Ward, S., Burton, J., \& Wilson, C. (2003). The role of mother-child joint play in the early development of children's conduct problems: a longitudinal observational study. Social Development, 12(3), 361-378.

Gardner, F. E. M., Sonuga-Barke, E. J. S., \& Sayal, K. (1999). Parents anticipating misbehaviour: an observational study of strategies parents use to prevent conflict with behaviour problem children. Journal of Child Psychology and Psychiatry, 40(8), 1185-1196.

Gari, A., \& Kalantzi-Azizi, A. (1998). The influence of traditional values of education on Greek students' real and ideal self-concepts. The Journal of Social Psychology, 138(1), 5-12.

Germán, M., Gonzales, N. A., \& Dumka, L. (2009). Familism values as a protective factor for Mexican-origin adolescents exposed to deviant peers. The Journal of Early Adolescence, 29(1), 16-42.

Goodnow, J. J. (1997). Parenting and the transmission and internalization of values: from social-cultural perspectives to within-family analyses. In J. E. Grusec, \& L. Kuczynski (Eds.), Parenting and children's internalization of values: A handbook of contemporary theory (pp. 333-361). New York: Wiley.

Grolnick, W. S., Deci, E. L., \& Ryan, R. M. (1997). Internalization within the family: the self-determination theory perspective. In J. E. Grusec, \& L. Kuczynski (Eds.), Parenting and children's internalization of values: A handbook of contemporary theory (pp. 135-161). Hoboken, NJ US: John Wiley \& Sons Inc.

Grolnick, W. S., \& Ryan, R. M. (1989). Parent styles associated with children's self-regulation and competence in school. Journal of Educational Psychology, 81, $143-154$

Grusec, J. E. (2002). Parenting socialization and children's acquisition of values. In M. H. Bornstein (Ed.), Handbook of parenting (2nd ed.).. Practical issues in parenting, Vol. 5 (pp. 143-167) Mahwah, NJ US: Lawrence Erlbaum Associates Publishers.

Grusec, J. E., \& Goodnow, J. J. (1994). Impact of parental discipline methods on the child's internalization of values: a reconceptualization of current points of view. Developmental Psychology, 30(1), 4-19.

Grusec, J. E., \& Kuczynski, L. (1980). Direction of effect in socialization: a comparison of the parent's versus the child's behavior as determinants of disciplinary techniques. Developmental Psychology, 16, 1-9.

Grusec, J. E., \& Kuczynski, L. (1997). Parenting and children's internalization of values: A handbook of contemporary theory. Hoboken, NJ US: John Wiley \& Sons Inc.

Grusec, J. E., \& Lytton, H. (1988). Social development: History, theory, and research. New York, NY US: Springer-Verlag Publishing.

Hair, J. F., Jr., Anderson, R. E., Tatham, R. L., \& Black, W. C. (1998). Multivariate data analysis (5th ed.). Upper Saddle River, NJ: Prentice-Hall.

Hardy, S. A., \& Carlo, G. (2005). Religiosity and prosocial behaviours in adolescence: the mediating role of prosocial values. Journal of Moral Education, 34(2), 231-249.

Harrison, A. O., Wilson, M. N., Pine, C. J., \& Chan, S. Q. (1990). Family ecologies of ethnic minority children. Child Development, 61(2), 347-362.

Holden, G. W. (1983). Avoiding conflict: mothers as tacticians in the supermarket. Child Development, 54(1), 233-240.

Holden, G. W., \& West, M. J. (1989). Proximate regulation by mothers: a demonstration of how differing styles affect young children's behavior. Child Development, 60(1), 64-69.

Kasser, T., Ryan, R. M., Zax, M., \& Sameroff, A. J. (1995). The relations of maternal and social environments to late adolescents' materialistic and prosocial values. Developmental Psychology, 31(6), 907-914.

Keijsers, L., Frijns, T., Branje, S. J. T., \& Meeus, W. (2009). Developmental links of adolescent disclosure, parental solicitation, and control with delinquency: moderation by parental support. Developmental Psychology, 45(5), 1314-1327.

Kim, Y.-M., \& Neff, J. A. (2010). Direct and indirect effects of parental influence upon adolescent alcohol use: a structural equation modeling analysis. Journal of Child \& Adolescent Substance Abuse, 19(3), 244-260.

Kiuru, N., Aunola, K., Nurmi, J.-E., Leskinen, E., \& Salmela-Aro, K. (2008). Peer group influence and selection in adolescents' school burnout: a longitudinal study. Merrill-Palmer Quarterly: Journal of Developmental Psychology, 54(1), 23-55.

Knafo, A., \& Assor, A. (2007). Motivation for agreement with parental values: desirable when autonomous, problematic when controlled. Motivation and Emotion, 31, 232-245.

Knafo, A., \& Schwartz, S. S. (2004). Identity formation and parent-child value congruence in adolescence. British Journal of Developmental Psychology, 22, 439-458.

Kosterman, R., Hawkins, J. D., Guo, J., Catalano, R. F., \& Abbott, R. D. (2000). The dynamics of alcohol and marijuana initiation: patterns and predictors of first use in adolescence. American Journal of Public Health, 90(3), 360-366.

Kuczynski, L. (1984). Socialization goals and mother-child interaction: strategies for long-term and short-term compliance. Developmental Psychology, 20(6), 1061-1073.

Laible, D. J., Carlo, G., \& Roesch, S. (2004). Pathways to self-esteem: the role of parent and peer attachment, empathy, and social behaviors. Journal of Adolescence, 27, 703-716.

Laird, R., Marrero, M., \& Sentse, M. (2010). Revisiting parental monitoring: evidence that parental solicitation can be effective when needed most. Journal of Youth and Adolescence, 39(12), 1431-1441.

Lansford, J. E., Malone, P. S., Stevens, K. I., Dodge, K. A., Bates, J. E., \& Pettit, G. S. (2006). Developmental trajectories of externalizing and internalizing behaviors: factors underlying resilience in physically abused children. Development and Psychopathology, 18(1), 35-55.

Larson, R., \& Richards, M. (1991). Daily companionship in late childhood and early adolescence: changing developmental contexts. Child Development, 62, 284-3000.

Ludwig, K. B., \& Pittman, J. F. (1999). Adolescent prosocial values and self-efficacy in relation to delinquency, risky sexual behavior, and drug use. Youth \& Society, 30(4), 461-482.

Maccoby, E. E., \& Martin, J. A. (1983). Socialization in the context of the family: parent-child interaction. In E. M. Hetherington, \& P. H. Mussen (Eds.), Handbook of child psychology. Socialization, personality, and social development, Vol. 4 (pp. 1-101). New York: Wiley.

Milevsky, I. M., Szuchman, L., \& Milevsky, A. (2008). Transmission of religious beliefs in college students. Mental Health, Religion E Culture, 11(4), 423-434.

Mounts, N. S. (2000). Parental management of adolescent peer relationships: what are its effects on friend selection? In K. A. Kerns, J. M. Contreras, \& A. M. Neal-Barnett (Eds.), Family and peers: Linking two social worlds (pp. 169-193) Westport, CT US: Praeger Publishers/Greenwood Publishing Group.

Mounts, N. S. (2002). Parental management of adolescent peer relationships in context: the role of parenting style. Journal of Family Psychology, 16(1), 58-69.

Mounts, N. S., \& Steinberg, L. (1995). An ecological analysis of peer influence on adolescent grade point average and drug use. Developmental Psychology, 31(6), 915-922. 
Mueller, R. A. (2006). Values and identity in prosocial and at-risk youth: the role of value endorsement, value salience, and moral identity in behavior. Dissertation Abstracts International: Section B: The Sciences and Engineering, Vol. 67(3-B).

Nathanson, A. I. (1999). Identifying and explaining the relationship between parental mediation and children's aggression. Communication Research, 26(2), $124-143$.

Nathanson, A. I. (2001). Parent and child perspectives on the presence and meaning of parental television mediation. Journal of Broadcasting E Electronic Media, 45(2), 201-220.

Nathanson, A. I., Eveland, W. P., Jr., Park, H.-S., \& Paul, B. (2002). Perceived media influence and efficacy as predictors of caregivers' protective behaviors. Journal of Broadcasting \& Electronic Media, 46(3), 385-410.

Niemiec, C. P., Ryan, R. M., \& Deci, E. L. (2010). Self-determination theory and the relation of autonomy to self-regulatory processes and personality development. In R. H. Hoyle (Ed.), Handbook of personality and self-regulation (pp. 169-191).

Nikken, P., \& Jansz, J. (2006). Parental mediation of children's videogame playing: a comparison of the reports by parents and children. Learning, Media and Technology, 31(2), 181-202.

Padilla-Walker, L. M. (2006). “Peers I can monitor, it's media that really worries me!” Parental cognitions as predictors of proactive parental strategy choice. Journal of Adolescent Research, 21, 56-82.

Padilla-Walker, L. M. (2007). Characteristics of mother-child interactions related to adolescents' positive values and behaviors. Journal of Marriage and Family, 69(3), 675-686.

Padilla-Walker, L. M., \& Carlo, G. (2007). Personal values as a mediator between parent and peer expectations and adolescent behaviors. Journal of Family Psychology, 21, 538-541.

Padilla-Walker, L. M., Christensen, K. J., \& Day, R. D. (2011). Proactive parenting practices during early adolescence: a cluster approach. Journal of Adolescence, $34,203-214$

Padilla-Walker, L. M., \& Coyne, S. M. (2011). “Turn that thing off!” parent and adolescent predictors of proactive media monitoring. Journal of Adolescence, $34,705-715$

Padilla-Walker, L. M., Coyne, S. M., Fraser, A. M., Dyer, W. J., \& Yorgason, J. B. Parents and adolescents growing up in the digital age: latent growth curve analysis of proactive media monitoring. Journal of Adolescence, in press.

Padilla-Walker, L. M., Harper, J. M., \& Bean, R. A. (2011). Pathways to parental knowledge: the role of family process and family structure. Journal of Early Adolescence, 31, 604-627.

Padilla-Walker, L. M., \& Thompson, R. A. (2005). Combating conflicting messages of values: a closer look at parental strategies. Social Development, 14(2), 305-323.

Peterson, C., \& Seligman, M. E. P. (2004). Character strengths and virtues: A handbook and classification. Washington, DC: Oxford University Press.

Piko, B. F., \& Kovács, E. (2010). Do parents and school matter? Protective factors for adolescent substance use. Addictive Behaviors, 35(1), 53-56.

Pratt, M. W., Hunsberger, B., Pancer, S. M., \& Alisat, S. (2003). A longitudinal analysis of personal values socialization: correlates of a moral self-ideal in late adolescence. Social Development, 12(4), 563-585.

Raine, T. R., Jenkins, R., Aarons, S. J., Woodward, K., Fairfax, J. L., El-Khorazaty, M. N., et al. (1999). Sociodemographic correlates of virginity in seventh-grade Black and Latino students. Journal of Adolescent Health, 24(5), 304-312.

Romero, E., Sobral, J., Luengo, M. A., \& Marzoa, J. A. (2001). Values and antisocial behavior among Spanish adolescents. The Journal of Genetic Psychology: Research and Theory on Human Development, 162(1), 20-40.

Ryan, R. M., \& Connell, J. P. (1989). Perceived locus of causality and internalization: examining reasons for acting in two domains. Journal of Personality and Social Psychology, 57, 749-761.

Salmela-Aro, K., \& Tynkkynen, L. (2010). Trajectories of life satisfaction across the transition to post-compulsory education: do adolescents follow different pathways? Journal of Youth and Adolescence, 39(8), 870-881.

Schwartz, S. H. (1997). Values and culture. In D. Munro, S. Carr, \& J. Schumaker (Eds.), Motivation and culture (pp. 69-84). New York: Routledge.

Sharma, S., Durand, R. M., \& Gur-Arie, O. (1981). Identification and analysis of moderator variables. Journal of Marketing Research, 18, 291-300.

Siegel, A., \& Scovill, L. C. (2000). Problem behavior: the double symptom of adolescence. Development and Psychopathology, 12, 763-793.

Silk, J. S., Morris, A. S., Kanaya, T., \& Steinberg, L. (2003). Psychological control and autonomy granting: opposite ends of a continuum or distinct constructs? Journal of Research on Adolescence, 13, 113-128.

Simpkins, S. D., Davis-Kean, P. E., \& Eccles, J. S. (2006). Math and science motivation: a longitudinal examination of the links between choices and beliefs. Developmental Psychology, 42, 70-83.

Simons, L. G., Simons, R. L., \& Conger, R. D. (2004). Identifying the mechanisms whereby family religiosity influences the probability of adolescent antisocial behavior. Journal of Comparative Family Studies, 35(4), 547-563.

Tarry, H., \& Emler, N. (2007). Attitude, values and moral reasoning as predictors of delinquency. British Journal of Developmental Psychology, 25(2), 169-183.

Ward, J. H. (1963). Hierarchical grouping to optimize an objective function. Journal of the American Statistical Association, $58,236-244$.

Wigfield, A., \& Cambria, J. (2010). Students' achievement values, goal orientations, and interest: definitions, development, and relations to achievement outcomes. Developmental Review, 30(1), 1-35. 